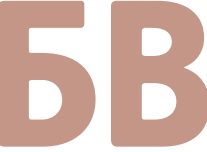

Ресурсы

и технологии

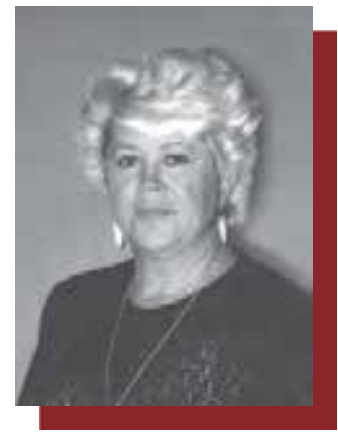

Юлия Николаевна

Дрешер,

директор Республиканского медицинского библиотечно-

инфорлационного иентра, доктор педагогических наук, профессор,

лауреат прелии

Правительства РФ в области образования (г. Казань)
Разработка

и формирование

системы

управления

качеством в

Республиканском

медицинском

библиотечно-

информационном

центре Татарстана

В статье изложен опыт внедрения систель менеджмента качества (СМК) и практический опыт решения проблем, возникающих при разработке, внедрении и сертификации СМК на соответствие требованиям международного стандарта ИСО 9001-2008.

Ключевые слова: систела менеджлента качества, библиотечный центр, политика в области качества, миссия, руководство по качеству, стандарт, стратегия, сертификация.

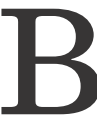

условиях рыночных отношений актуальность управления качеством определяется его направленностью на обеспечение такого уровня качества продукции и услуг, который сможет полностью удовлетворить запросы потребителей. Высокое качество является одним из основных критериев конкурентоспособности продукции и услуг. Без обеспечения стабильного качества, соответствующего требованиям потребителей, невозможно рационально интегрировать национальную экономику в мировое хозяйство и занять в нем достойное место.

Процессы интеграции в современных условиях развития мирового сообщества объективно необратимы, поэтому современная концепция управления качеством продукции и услуг для достижения намеченных целей предприятий (библиотек) становится приоритетной среди других направлений управления (см. рис. 1).

Библиотеки в условиях жесткой конкуренции на рынке информационных услуг стремятся к развитию, обеспечивающему их востребованность и процветание. Но у каждой из них своя специфика, свой путь [1]. 


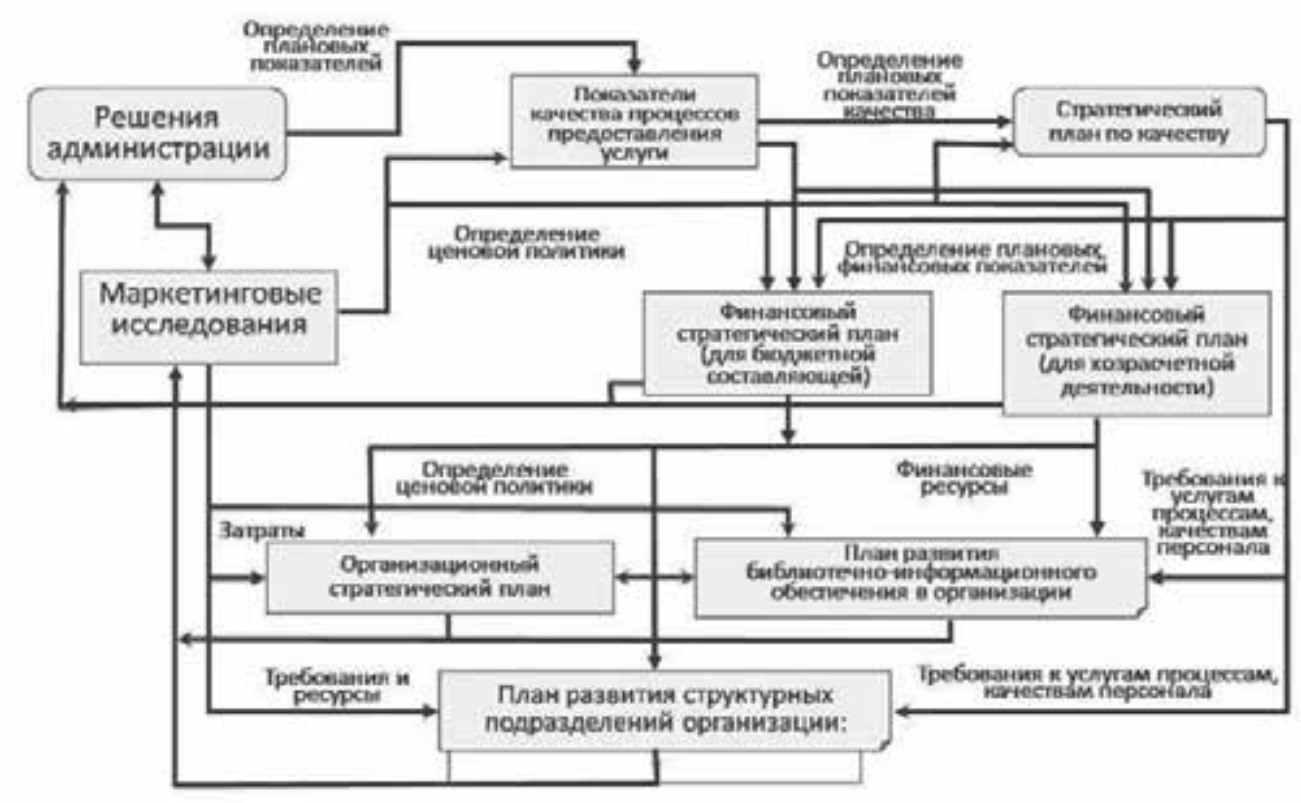

Рис. 1. Концепция развития систелы управления качествол инфорлационнобиблиотечной и библиографической продукщии и услуг на качество процессов, к внедрению инно о ац ионны х решений в работе, мотивация сотрудников оказалась поставлена чуть ли не на последнее место. В результате в начале внедрения СМК возникли проблемы. Одна из ошибок заключалась в том, что не были подготовлены специалисты для проведения внутреннего аудита, отсутствовало понимание необходимости внедрения СМК. И мы обратились к тому, с чего следовало начи-

нать - к мотивации персонала, его обучению.
Проводились разнообразные семинары через Институт дополнительного профессионального образования, Академию стандартизации, практиковались выезды на рабочие места, «дни качества» и т.д. Таким образом стала реализовываться новая политика кадрового обеспечения Центра, был разработан план повышения квалификации в области менеджмента качества, люди начали понимать, что от них требуется, и стали осмысленно включаться в работу [2].

Был создан координационный совет по качеству, который рассматривает новые документы и отсеивает ненужные (на первом этапе, по неопытности, было введено много лишних, дополнительных документов). Родилась идея создания внутреннего сайта по СМК, где бы находились все уже зарегистрированные и прошедшие процедуру утверждения документы (первые экземпляры). Это намного улучшило и упорядочило документооборот в СМК.

Рассматривая внедрение СМК как один из организационных аспектов инноваций, направленных на повышение качества управления Центром, мы исходили из того, что система должна представлять собой совокупность организационной структуры, методик, процессов и ресурсов, необходимых для осуществления политики в области качества посредством планирования и управления (см. рис. 2). Руководство Центра обозначило следующие основные требования: система должна стать компактной, понятной всем подразделениям, удобной, не перегруженной документами и сертифицированной в российской и международной системах сертификации. Кроме того, СМК должна приносить практическую пользу Центру, нием единых стандартов и форматов, влияющих 


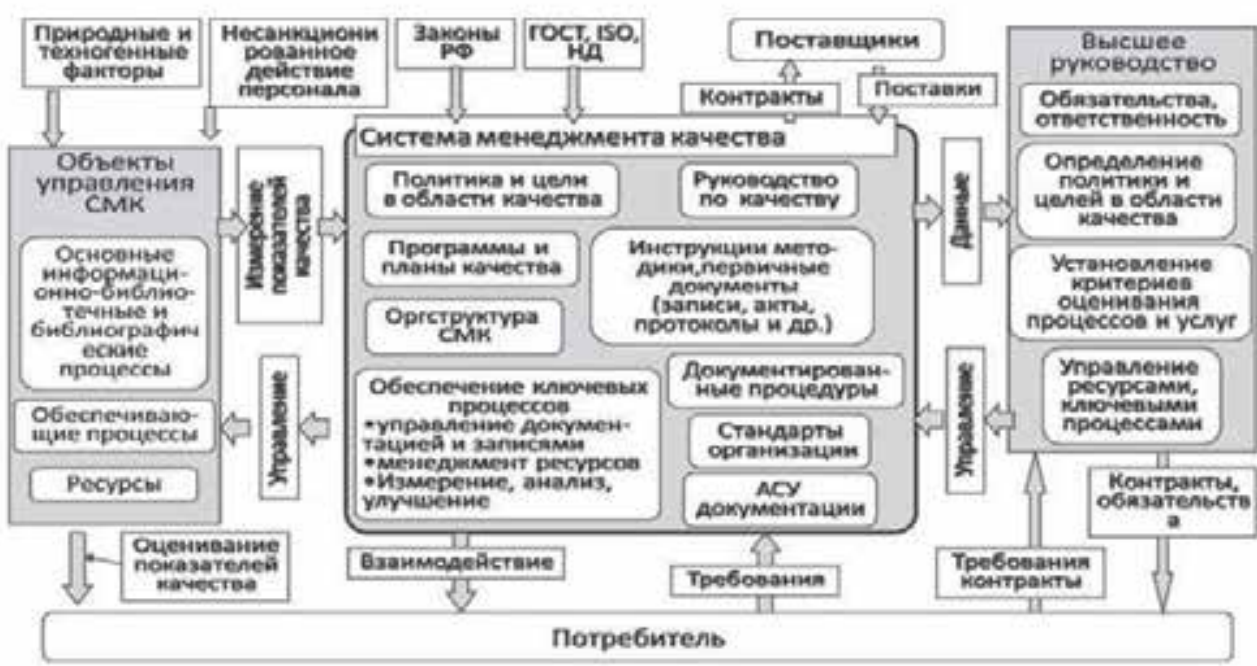

Рис. 2. Взаилодействие СМК с объектали и субъектали управления [3]

способствовать улучшению его работы во всех направлениях. С учетом этого в 2006 г. методический совет Центра принял решение о разработке положения о СМК и внедрении такой системы в управление Центром в соответствии с требованиями стандарта ИСО 9001-2001. Для реализации этого решения была создана рабочая группа (за прошедшие годы ее состав неоднократно менялся).

На начальной стадии руководством Центра было проведено самообследование - внутренний аудит собственной структуры управления, используемых методов управления и основных процессов, влияющих на эффективность деятельности Центра. Основная цель проведения самооценки - получение всесторонней информации для выработки плана мероприятий по созданию СМК, а также выявление потенциала для улучшения деятельности Центра и проведения первоочередных корректирующих действий [4].

\section{Опыт внедрения}

В соответствии с «Положением о разработке и внедрении системы менеджмента качества в РМБИЦ» разработаны «Политика в области качества РМБИЦ» и «Миссия РМБИЦ» (две редакции), которые после обсуждения на заседании методического совета в июле 2007 г. были утверждены приказом директора и доведены до сведения персонала.

Следующим этапом внедрения СМК явилась разработка системы организационно-распорядительной документации, которая регламентирует полномочия и ответственность должностных лиц, подразделений и отдельных сотрудников Центра. Важным элементом такой документации являются положение об отделах, секторах, библиотеках-филиалах и должностные инструкции.

Далее была сформирована организационная структура управления Центром, выделены процессы согласно стандарту ИСО 9001-2001, определены и назначены владельцы процессов, ответственные за перспективное планирование, ресурсное обеспечение и эффективность процесса; определены руководители, ответственные за текущее планирование и ведение процесса с целью достижения запланированных результатов.

Выявить весь состав процессов сразу является сложной задачей, поэтому сначала был сформирован первый вариант перечня, чтобы можно было начать работу по их документированию. Затем этот перечень корректировался с целью более полного отражения состава существующих процессов. Определению структуры процессов - состава и содержания 
отдельных его шагов - способствовало применение специально разработанных форм, а также карт процессов.

После назначения ответственных за качество в подразделениях и уполномоченного по качеству Центра и их обучения аудиторы по внутренним проверкам и персонал Центра по документированию процессов СМК также прошли обучение. Параллельно уполномоченные по качеству разрабатывали базовые стандарты Центра. В числе подготовленных документов - «Порядок разработки и построения положения об отделах центра», «Правила поведения и внутреннего распорядка», «Внутренний аудит», «Правила разработки должностных инструкций и функциональных обязанностей сотрудников центра», «Порядок документирования процессов». Разработчики документов прошли соответствующее обучение по программе «Методы управления качеством».

Не реже одного раза в месяц проходили заседания рабочей группы по качеству, на которые приглашались разработчики стандартов организации и руководители структурных подразделений, участвовавшие в согласовании документов. Наиболее трудоемкой с точки зрения формирования методологии оценки деятельности оказалась разработка стандарта «Показатели (индикаторы) оценки качества информационно-библиотечных, библиографических услуг, продукции и эффективности деятельности РМБИЦ». Документы рассматривались на совместных заседаниях расширенного методического совета, затем координационного совета по качеству и рабочей группы с привлечением должностных лиц, ответственных за организацию процессов.

\section{Этапы документирования системы менеджмента качества}

Вся документация впоследствии была разделена на несколько уровней.

Высший уровень - это «Руководство по качеству», в котором любое заинтересованное лицо (потребитель, аудитор или вновь принятый сотрудник) может найти общую информацию о Центре и получить представление о его политике в области качества, миссии, целях, стратегии, основных управленческих и производственных процессах.

Информация более частного характера содержится в документах второго уровня. Это стандарты по управлению отдельными процессами, в частности «Управление производственной средой», «Процесс взаимодействия с внешней средой и заинтересованными сторонами», «Кадровая политика». Документы, как правило, находятся у лиц, отвечающих за данный процесс, что обеспечивает сотрудникам структурного подразделения постоянный доступ к ним. Изучение такого документа (стандарта) поможет новому сотруднику быстро ознакомиться с тем, как должен осуществляться данный вид деятельности, в каких процессах сотрудник лично задействован, с кем должен контактировать, получая информацию и необходимые ресурсы, и кому по технологической цепочке должен дальше передать результат своей работы.

К третьему уровню документации отнесены детальные методики осуществления конкретной деятельности, технологические карты, должностные инструкции, рабочие инструкции, шаблоны, формы и т. д. Для каждой должности должен иметься свой набор документов, исключающий вольную трактовку сотрудниками своих прав, обязанностей и полномочий и позволяющий сократить время, необходимое для индивидуального введения каждого нового сотрудника в курс дела.

Периодически на общих собраниях коллектива, расширенных заседаниях методического совета Центра коллектив информировался о положительных результатах, которые уже достигнуты с помощью СMК, и дальнейших шагах. Для того чтобы СМК действовала и постоянно развивалась, разработанная документация сразу же вводилась в оборот после процедуры согласований и утверждения координационным советом. Внедрение системы отслеживалось при помощи внутреннего аудита под руководством и контролем уполномоченного по качеству. Логическим завершением разработки и внедрения СМК Центра стало решение о сертификации системы на соответствие требованиям стандарта ИСО 9001-2008.

Согласно решению методического совета в июне и сентябре 2009 г. в Центре проводилась сертификационная проверка СМК. Она охватывала информационно-библиотечные услуги и информационно-библиотечную продукцию. При выборе сертифицирующего органа принималось во внимание, что в первую очередь он должен:

- иметь международное признание, т. е. его оценка должна удовлетворять не только российских потребителей интеллектуального продукта и услуг Центра, но и зарубежных партнеров;

- работать в России и иметь полномочия по выдаче сертификата соответствия СМК требованиям стандарта ИСО 9001-2008.

Сертификацию СМК Центра проводила Ассоциация по сертификации «Русский Регистр" (Поволжское отделение), имеющая 26 инспекций (в том числе в Казани), 7 региональных управлений в РФ, 5 представительств в России и 12 - в Европе, Азии, Америке. «Русский Регистр» проводит работы по сертификации СМК более чем в 140 странах и обеспечивает поддержку сертифицированным организациям. 


\section{Внешний аудит}

Этап «Поддержка и постоянное улучшение результативности» является основным этапом жизненного цикла СМК. Он включает в себя проведение внутренних и внешних аудитов. Аудит - это систематическая проверка СМК с последующим анализом соответствия деятельности Центра в области качества запланированным мероприятиям и поставленным целям. Аудит как составная часть СМК Центра является инструментом непрерывного улучшения качества. По результатам аудита определяются слабые места, проводятся корректирующие действия, контролируется действенность проведенных ранее мероприятий. Совершенствование деятельности центра невозможно без периодического анализа фактического состояния работы по качеству и ее результатов. Работа по документированию процессов СМК позволила провести такой анализ, разработать современную нормативную и рабочую документацию по всем направлениям деятельности, исключить дублирование процедур, создать систему контроля на основе планов по качеству, повысить эффективность организационной структуры Центра, четко распределить полномочия и ответственность на всех уровнях руководства, сформулировать цели и выделить ключевые процессы, более эффективно распоряжаться имеющимися ресурсами.

В Центре проведено два внешних аудита: предварительный и сертификационный. После проверки выполнения намеченных корректирующих действий по результатам сертификационного аудита был выдан сертификат соответствия СМК требованиям стандарта ИСО 9001-2008. Благодаря членству «Русского Регистра» в международной сертификационной сети IQNet, объединяющей ведущие организации по сертификации 36 стран, в дополнение к основному сертификату Центр получил сертификат единого международного образца IQNet на соответствие CMК Центра требованиям стандарта ИСО 9001-2008.

Однако необходимо понимать, что стандарт ISO не догма, а только инструмент для организации работы по внедрению принципов менеджмента качества. Главной задачей Центра было не создание СМК и ее сертификация, а внедрение и использование современных методов управления с целью повышения качества оказания информационнобиблиотечных услуг и продуктов.

Рабочая группа, занимавшаяся разработкой и внедрением СMК, накопила большой опыт практической работы в этой области.

\section{Наши рекомендации}

В настоящее время ведется создание методических рекомендаций в области разработки и внедрения СМК в медицинские библиотеки России и использования процессного подхода в управлении.

Таким образом, можно констатировать:

- процессный подход как инструмент создания и совершенствования СМК на основе стандарта ИСО 9001-2008 обладает высоким организационно-методическим потенциалом;

- полноценное внедрение процессного подхода позволило обеспечить новое качество управления центром за счет прозрачности механизма функционирования и управления процессами и получить на этой основе дополнительные возможности постоянного совершенствования СМК;

- процессный подход может быть эффективно использован для построения интегрированных систем менеджмента применительно к различным направлениям деятельности Центра: информационно- 
библиотечному, библиографическому, изда-тельско-полиграфическому и т.д.;

- стандарт ИСО 9001-2008 предоставляет значительную свободу в выделении процессов СМК; эта характерная черта стандарта обусловливает большое разнообразие возможных моделей построения СМК; в настоящее время она базируется не только на требованиях Министерства здравоохранения РФ, Министерства культуры РФ и Республики Татарстан, стандарта ИСО 9001-2008, но и на внутренних стандартах Центра, регулирующих большинство процессов.

Это позволяет Центру предлагать высококачественные информационно-библиотечные и библиографические продукты и услуги, ориентированные на полное и качественное удовлетворение запросов потребителей - медицинских работников.

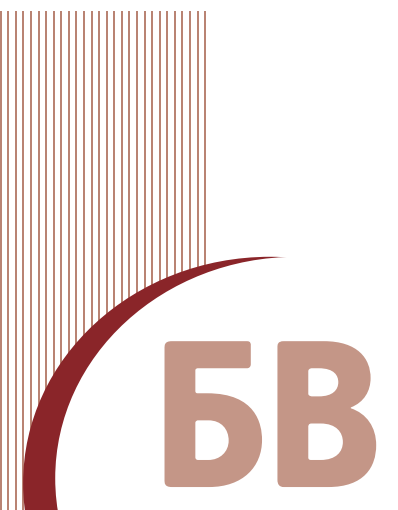

\section{Ресурсы \\ и технологии}

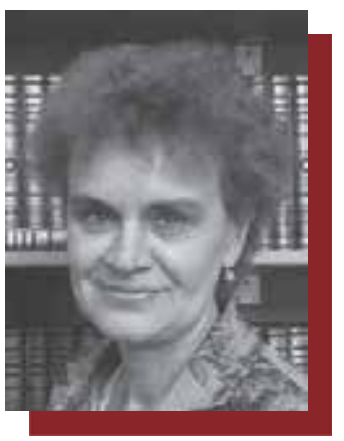

Надежда Сергеевна Масловская, залеститель заведующей отделол справочно-библиографического обслуживания

Российской государственной библиотеки

\section{Список источников}

1. Ахмадова Ю.А. Менеджмент качества и библиотека: учеб.-практ. пособие / Ю.А. Ахмадова, Е.Я. Галимова. - М.: Либерея-Бибинформ, 2007. $88 \mathrm{c.}$

2. Дрешер Ю.Н. Некоторые подходы к управлению качеством в современной библиотеке / / Менеджмент качества - путь к успешной библиотеке: материалы Всеросс. науч.-практ. конф., Санкт-Петербург, 23 ноября 2007 г. - СПб., 2007. - С. 43-57.

3. Никитин B.A. Управление качеством на базе стандартов ИСО 9000-2000. Политика. Оценка. Формирование. Ресурсы / В.А.Никитин [и др.]. СПб.: Питер; Питер Принт, 2002. -261 с. - (Серия «Теория и практика менеджмента»).

4. Шарипов С.В. Система менеджмента качества/ С.В. Шарипов, Ю.В. Толстова. -СПб.: Питер, 2004. $-192 \mathrm{c}$.

Иллюстративный материал предоставлен авторол статьи.

\section{Профиль}

комплектования библиотек как инструмент управления

\section{справочно- библиографи- ческим фондом}

Освещены разработка и особенности развития профилей колплектования библиотек в историческом и источниковедческом аспектах на примере Центрального справочнобиблиографического фонда Российской государственной библиотеки. Прослеживается динамика форлирования фонда и роль профиля как инструлента управления.

Ключевые слова: профиль колплектования, управление фондом, справочно-библиографический фонд.

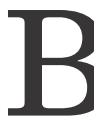

процессе формирования и использования фондов библиотеки руководствуются многоуровневой совокупностью нормативноправовых документов, в которую входят законы 